\title{
Liên kết đại học - công nghiệp trong thúc đẩy chuyển giao công nghệ: nghiên cứu tại các trường đại học công nghệ và kĩ thuật Việt Nam
}

\author{
Hoàng Lê Ngọc Anh \\ SSHPA System \\ E-mail: hoanglengocanh1996@gmail.com
}

Hà Nội, 12-06-2019

Trong xu hướng của nền kinh tế tri thức trên phạm vi toàn cầu những năm gần đây, hệ thống đổi mới quốc gia (NIS) có vai trò quan trọng đối với sự phát triển bền vững. Trong đó, giáo dục đại học và nền công nghiệp đều là những nhân tố thiết yếu với vai trò riêng, đồng thời thì sự kết hợp cả hai yếu tố cũng có tác động lớn tới hoạt động chuyển giao công nghệ, thúc đẩy nền kinh tế quốc gia.

Hệ thống đổi mới quốc gia tại Việt Nam vẫn đang trong giai đoạn đầu thực hiện, và còn đối mặt với nhiều thách thức và yếu điểm. Đặc biệt là sự xa rời giữa các cơ sở nghiên cứu, bao gồm trường đại học với lĩnh vực sản xuất thực tế, và chưa khai mở hết tiềm năng sự sáng tạo và chuyển giao kiến thức ở các trường đại học này. 


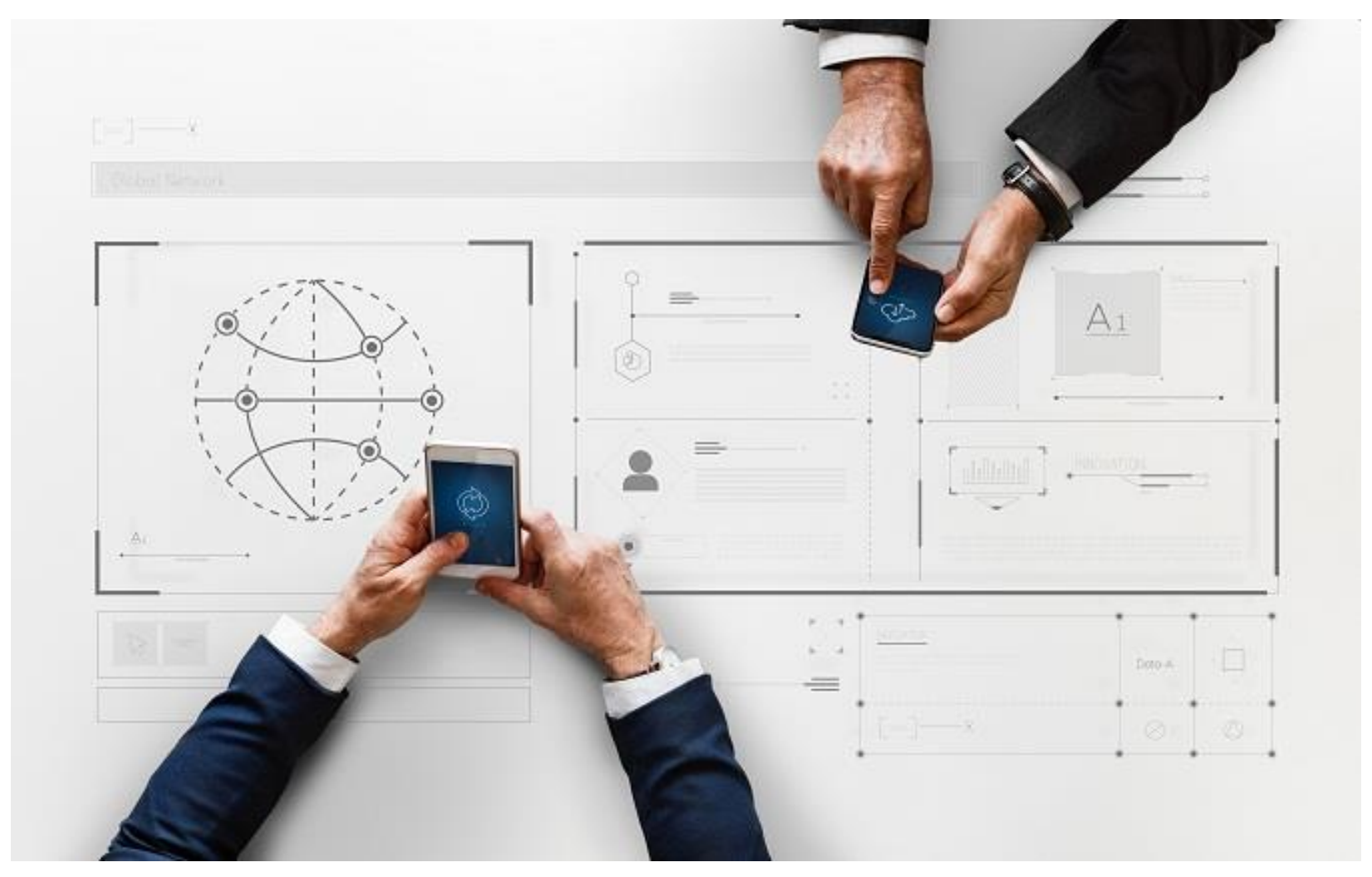

(Nguồn: Pexels)

Cuối tháng 1 năm 2019, hai tác giả đến từ trường Đại học Bách khoa Hà Nội: Lê Hiếu Học và Nguyễn Đức Trọng đã tìm hiểu về liên kết giữa các trường đại học công nghệ - kĩ thuật với công nghiệp ở Việt Nam. Nghiên cứu với tên gọi University-Industry Linkages in Promoting Technology Transfer: A Study of Vietnamese Technical and Engineering Universities được công bố trên tạp chí Science, Technology and Society [2017 JIF = 0.707; 2018 CiteScore = 1.03] thuộc nhà xuất bản SAGE [1].

Khảo sát từ 570 giảng viên 5 trường đại học công nghệ và kĩ thuật của Việt Nam cho thấy các loại hình liên kết giữa trường đại học và công nghiệp, động lực và những rào cản còn tồn tại trong liên kết này. Có sự khác biệt giữa nhìn nhận của những người trả lời khảo sát, tuy nhiên có thể rút ra những kết quả quan trọng:

- Giai đoạn 2010-2015, các hoạt động liên kết của trường đại học và công nghiệp diễn ra thường xuyên, đáng kể hơn so với giai đoạn 2005-2009. Có thể giải thích đây là hiệu quả của việc ban hành, chỉnh sửa các văn bản pháp lý về giáo dục, khoa học và công nghệ. Tuy nhiên ở cả hai giai đoạn, hoạt động liên kết chủ yếu là hỗ trợ sinh viên học bổng hoặc thực tập nghề nghiệp. Các hoạt động khác như nghiên cứu hay chuyển giao công nghệ còn hạn chế.

- Giảng viên được khảo sát nhận thức được tất cả những động lực liên kết giữa trường đại học với công nghiệp, tuy nhiên chú trọng hơn cả là những hoạt động này hỗ 
trợ cho công tác giảng dạy, ví dụ như cải thiện cơ sở vật chất giảng đường, nâng cao danh tiếng của trường và tạo cho sinh viên cơ hội tiếp cận môi trường làm việc thực tế cũng như thực hiện nghiên cứu tại các công ty.

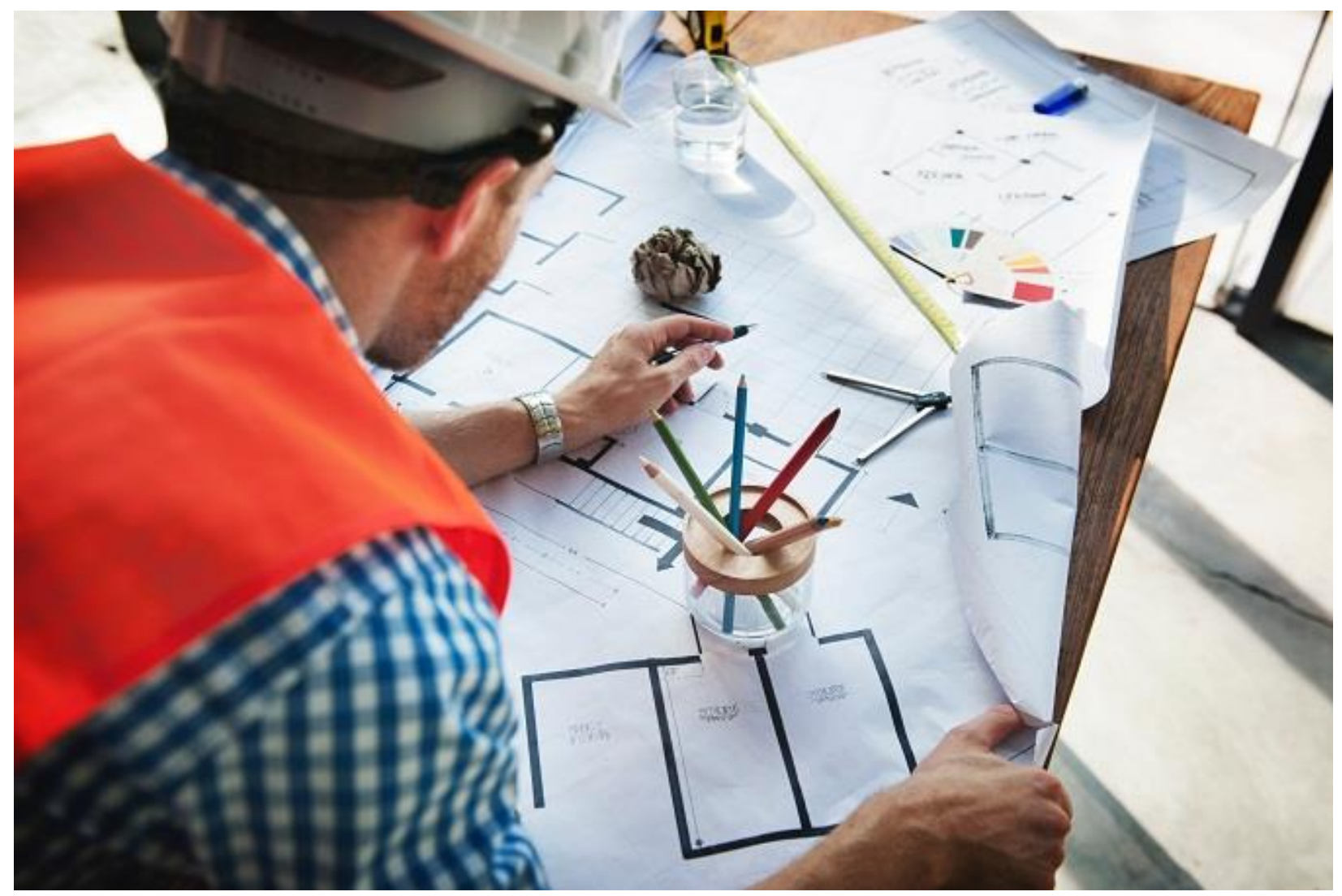

(Nguồn: $\underline{\text { Pexels) }}$

- Những hạn chế có ảnh hưởng nhiều nhất trong liên kết giữa trường đại học và công nghiệp bao gồm sự khác biệt về mục tiêu nghiên cứu, vị trí địa lý, sự tự tin của giảng viên và quyền lựa chọn đề tài nghiên cứu, cũng như quy định, điều luật của trường đại học.

Dựa trên phân tích về tình trạng hiện tại của liên kết trường đại học và công nghiệp, các tác giả đưa ra một số đề xuất đối với trường đại học, cơ sở công nghiệp và với chính phủ nhằm thúc đẩy nghiên cứu và chuyển giao công nghệ, tạo ra hiệu quả trong đầu tư khoa học [2] và tác động tích cực tới nền kinh tế quốc gia.

Note: Published in SciComm SSHPA on 8 June, 2019: https://sc.sshpa.com/post/5490.

\section{References:}


[1] Le, H. H. \& Nguyen, D. T. (2019). University-industry linkages in promoting technology transfer: A study of Vietnamese technical and engineering universities. Science, Technology and Society, 24(1), 73-100, DOI: 10.1177/0971721818821796.

[2] Vuong, Q. H. (2018). The (ir) rational consideration of the cost of science in transition economies. Nature Human Behaviour, 2, 5, DOI: 10.1038/s41562-017-0281-4. 